\title{
Las caras del poder en el teatro de Cervantes*
}

\author{
IgNACio ARELlAno**
}

\section{Resumen}

El artículo examina diversos aspectos del poder y la autoridad en el teatro de Cervantes, donde el tema se manifiesta en modalidades relacionadas con el género dramático: poder del amor y de la hermosura, poder del interés y del dinero, poder político o poder divino, son algunas de las vertientes que se advierten en las obras dramáticas cervantinas.

Palabras Clave: Cervantes; teatro del Siglo de Oro; poder; autoridad.

\section{Title: The faces of power in the theater of Cervantes}

\begin{abstract}
This article examines various aspects of power and authority in the theater of Cervantes, where the topic is manifested in a number of categories concerning the dramatic genre: power of love and the pulchritude, power of interest and money, political power or power of God... are some of the aspects that are found in the dramatic works of Cervantes.
\end{abstract}

Key Words: Cervantes; Golden Age theater; power; authority.

\section{Cómo citar este artículo / Citation}

Arellano, Ignacio (2017). «Las caras del poder en el teatro de Cervantes», Anales Cervantinos. 49, pp. 103-118, doi: http://dx.doi.org/10.3989/anacervantinos.2017.005.

* El presente trabajo se integra en el proyecto FFI2014-52007-P, Autoridad y poder en el teatro del siglo de oro. Estrategias, géneros, imágenes en la primera globalización, Ministerio de Economía y Competitividad, Gobierno de España. Dirección General de Investigación Científica y Técnica. Programa Estatal de Fomento de la Investigación Científica y Técnica de Excelencia.

** GRISO, Universidad de Navarra.iarellano@unav.es / ORCID iD: http://orcid.org/0000-00023386-3668. 
Muchas son las caras del poder ${ }^{1}$ y muchas sus imágenes en la literatura y en el teatro. En lo que se refiere al teatro de Cervantes, Jean Canavaggio $(2017)^{2}$ examina con su pericia habitual el poder y la autoridad en cuatro figuras de rey (en El trato de Argel, Los baños de Argel, La gran sultana y Pedro de Urdemalas), pero hay muchas otras manifestaciones de diversas categorías del "poder" en las piezas dramáticas cervantinas, que me propongo observar someramente. Las figuras del poder no se limitan, desde luego, al rey o actantes "políticamente poderosos", sino que revisten distintas modalidades. Estas modalidades quedan en buena parte definidas por los modelos genéricos teatrales, que requieren determinadas convenciones -se respeten o se contravengan- delimitadoras del tratamiento del tema y sus agentes.

\title{
EL PODER DEL AMOR Y LA HERMOSURA. ALGUNOS CONFLICTOS
}

El poder más reiterado en el teatro cervantino no corresponde a ninguna modalidad política: es el poder de la hermosura y del amor, que entra a veces en conflicto con otras instancias que se le enfrentan, la mayoría vencidas, alguna superior al mismo amor según los contextos.

Un modelo peculiar lo representa Arlaxa en El gallardo español ${ }^{3}$. La comedia se abre con una extravagante petición de la dama mora a su amante Alimuzel, al que le pide que le traiga preso al español don Fernando, cuyas hazañas corren por toda Berbería:

\author{
Es el caso, Alimuzel \\ que a no traerme el cristiano \\ te será el amor tirano \\ y yo te seré cruel (p. 16).
}

Arlaxa parece experimentar un deseo con visos de atracción amorosa y sus ribetes de soberbia ( $c f r$. p. 42; p. 45 dice Oropesa: «de tu fama valerosa / que está enamorada creo»), e impone a Alimuzel una tiranía basada en la hermosura con la que tiene cautiva el alma del amante, quien pondera precisamente el poder extremo de ese «rostro divino / ángel que mora en la tierra» (p. 18):

En extremo poderosa

de dar tormento y placer,

1. Para aspectos generales, y ciertas modalidades del poder (y la autoridad) remito a trabajos anteriores y las publicaciones del proyecto de autoridad y poder que desde hace años desarrollan equipos de Oxford, Sorbonne Nouvelle, Munster y Navarra. Mencionaré ahora solo Arellano 2011; Arellano, Strosetzki y Williamson 2009; Williamson y Usunáriz 2013; Insúa y Schmelzer 2013; Arellano, Feros y Usunáriz 2012; Lourenço y Usunáriz 2012; Baraibar e Insúa 2012.

2. Agradezco al prof. Canavaggio que me haya facilitado su trabajo antes de la publicación.

3. Cito por la edición de Teatro completo de Cervantes, de Sevilla Arroyo y Rey Hazas. 
yelo que nos hace arder

en viva llama amorosa (p. 18).

Al comienzo de la tercera jornada los reyes de Alabez y Cuco exaltan el poder de la belleza de la misma Arlaxa, que puede dar leyes al mundo y parar a la Fortuna voltaria:

Cuco Hermosísima Arlaxa: tu belleza

puede volver del mesmo Marte airado

en mansedumbre su mayor braveza,

y dar leyes al mundo alborotado (p. 77).

Doblega también la voluntad del jarife Nacor, que por amor y deseo de Arlaxa está dispuesto a traicionar a su nación y su religión.

Arlaxa es, pues, un centro en cuyo torno gira una constelación de servidumbres amorosas sometidas a su belleza.

De diferente calidad es el amor que siente Margarita por don Fernando, el gallardo español. Margarita, escapada del monasterio y de un hermano codicioso, vestida de hombre, persigue a don Fernando, de quien se ha enamorado de oídas. En pos del galán llega a Orán, donde se hace prender cautiva para estar cerca del amado, en otro caso de entrega al poder irresistible del amor, que ciega el albedrío y la razón:

¡Oh amoroso desvarío

que ciegas el albedrío

y la razón tienes presa! (p. 65).

Al tono de comedia le corresponde el final feliz con los dos matrimonios (el de los moros Arlaxa y Alimuzel y el de los cristianos Fernando y Margarita), después de haber sorteado los obstáculos del cautiverio y la guerra. La ceguera amorosa (algo inverosímil) de Margarita, arrojada en busca de don Fernando, al que no conoce, a través de las guerras de Italia y Orán, no trae consecuencias negativas, pues el mundo del gallardo español queda caracterizado por la victoria de don Fernando y lo que este supone, como arquetipo de toda la nación y sus valores.

En La gran sultana la belleza y el amor subordinan incluso al fasto sacralizador que rodea al Gran Turco, cuya primera aparición en escena subraya la pompa del poder y la realeza del monarca a quien no pueden ni siquiera mirar al rostro (p. 374, «Entra a esta instante el Gran Turco con mucho acompañamiento [...] tiene Salec doblado el cuerpo y inclinada la cabeza, sin miralle el rostro...»):

La pompa y majestad deste tirano sin duda alguna sube y se engrandece

sobre las fuerzas del poder humano (p. 373). 
Pero como señala Canavaggio $(2017)^{4}$, «le prétendu “tyran" se rend aux désirs de sa captive», sometiéndose al irresistible poder del amor.

En diversas variantes este tema del poder universal del amor, a menudo enfrentado a la razón, reaparece en El trato de Argel (p. 846), La casa de los celos (p. 117), La entretenida (p. 561), o en general en El laberinto de amor..., como fuerza dominadora de los personajes, sumidos en el «ciego laberinto» (p. 465) de la pasión:

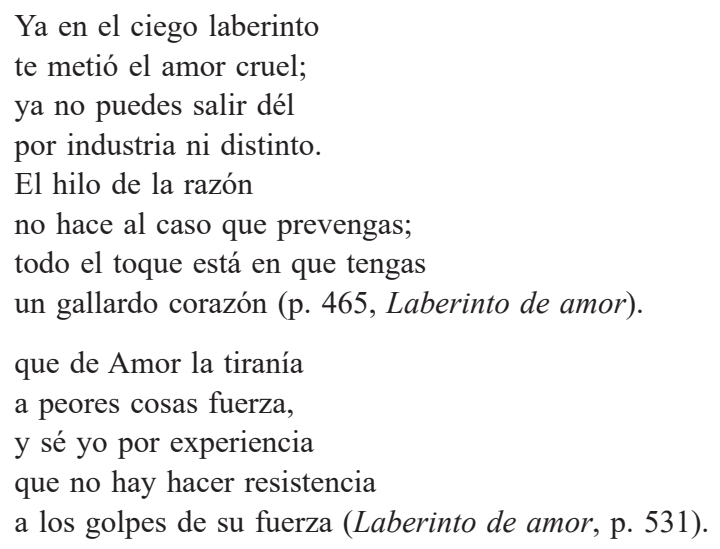

En ocasiones surgen, sin embargo, obstáculos y conflictos con fuerzas oponentes. Una de ellas, ambigua (en tanto es enemiga pero también derivada del amor) es la de los celos (La casa de los celos, Laberinto de amor...), pero destaca sobre todo la presión de los actantes "paternos" que proyectan enlaces matrimoniales no deseados por los enamorados, y que casi siempre oponen la fuerza del amor a la del interés.

En La entretenida (p. 623) el padre de Marcela se lamenta de las atropelladas decisiones amorosas de su hija, y protesta de los engaños de seductores embusteros. En Laberinto de amor, el duque de Novara pretende casar a su hija Rosamira con el criterio de la autoridad paterna que parece aceptar en principio su hija (p. 459: «Nunca al querer del padre fue siniestra»), pero en realidad el padre desconoce la voluntad de Rosamira, que ha elegido a Dagoberto, y no a Manfredo (carta de Dagoberto al duque, p. 536, «tu hija escogió lo que quizá tú no le dieras casándola contra su voluntad»). A la codicia de la hacienda atribuye Margarita en El gallardo español la actitud autoritaria y opresora de su hermano (actante paterno), que la mantiene soltera y pretende meterla en un convento.

El amor frente al poder del interés es un tema clásico que atrajo insistentemente la atención de Cervantes. Baste recordar el elaborado despliegue de la danza hablada del Quijote (II, 20) en las celebraciones de las

4. Compárese varios pasajes de la comedia en pp. 393, 408, 436, 439... 
bodas de Camacho, donde se escenifica el combate entre ambos oponentes ${ }^{5}$ :

Tras esta entró otra danza de artificio y de las que llaman habladas. Era de ocho ninfas, repartidas en dos hileras: de la una hilera era guía el dios Cupido, y de la otra, el Interés; aquel, adornado de alas, arco, aljaba y saetas; este, vestido de ricas y diversas colores de oro y seda. Las ninfas que al Amor seguían traían a las espaldas en pargamino blanco y letras grandes escritos sus nombres [...] Comenzaba la danza Cupido, y, habiendo hecho dos mudanzas, alzaba los ojos y flechaba el arco contra una doncella que se ponía entre las almenas del castillo, a la cual desta suerte dijo:

- Yo soy el dios poderoso en el aire y en la tierra $\mathrm{y}$ en el ancho mar undoso $\mathrm{y}$ en cuanto el abismo encierra en su báratro espantoso.

Nunca conocí qué es miedo; todo cuanto quiero puedo, aunque quiera lo imposible, $\mathrm{y}$ en todo lo que es posible mando, quito, pongo y vedo.

Acabó la copla, disparó una flecha por lo alto del castillo y retirose a su puesto. Salió luego el Interés y hizo otras dos mudanzas; callaron los tamborinos y él dijo:

- Soy quien puede más que Amor, y es Amor el que me guía; soy de la estirpe mejor que el cielo en la tierra cría, más conocida y mayor.

Soy el Interés, en quien pocos suelen obrar bien, y obrar sin mí es gran milagro; y cual soy te me consagro, por siempre jamás, amén.

El poder del amor aparece en forma de emblema escénico en La casa de los celos, donde sale el carro de Venus tirado de los leones de la montaña (p. 147), según representación del emblema 105 de Alciato «Potentissimus affectus amor», con su grabado de un carro cuyo auriga es Cupido, tirado por dos leones, enseñanza que Daza Pinciano comenta: el teatro cervantino Arellano (1997). 
La fuerza del león tiene vencida amor, si no es de amor jamás vencido, que a solo amor ser quiso Amor rendido a quien no hay cosa que no esté rendida.

El propio Cupido sale a escena encarnado en un actor, que muestra curiosas dicrepancias respecto del modelo arquetípico: va vestido, por decencia, obviamente («el dios Cupido, vestido, y con alas, flechas y arco desarmado», p. 148), pero sobre todo, como el texto pronunciado por Venus comenta de nuevo (p. 149) viene sin la venda en los ojos, con el arco desarmado y sin aljaba.

¿Quién ha sido tan poderoso para quitar la aljaba y venda al mismo dios Amor? La respuesta se mantiene en el universo emblemático también: es el Interés quien ha hecho todo esto a Cupido, según reflejan emblemas como el de Corrozet «Amour vaincu par argent» (Henkel-Schöne 1967: col. 1762).

La queja de los pastores en la misma comedia (p. 134) sobre el peso de la pobreza («Pesado contrapeso es la pobreza / para volar de amor ¡oh Lauso!, al cielo» $)^{6}$, alude igualmente, como señalan los editores, a un emblema de Alciato (el 120) donde el hombre ingenioso tiene alas en la mano izquierda que tienden a encumbrarlo, pero una piedra en la derecha (la pobreza) lo detiene. En la traducción de Daza Pinciano:

Colgado está a la derecha mano un canto y la simetría está encumbrada con unas alas que subirme en vano trabajan, porque tanto la pesada carga detiene, cuanto de este llano la pluma sube a la región no hollada, que ansí estuviera aquesta ingenio en alto si mi pobreza no impidiera el salto.

Amor, pobreza, autoridad paterna opresiva, interés e ingenio se funden en Pedro de Urdemalas, donde el zagal Clemente ve sus amorosos deseos impedidos por el padre de su amada Clemencia -más inclinado a conceder la mano de su hija a otros villanos ricos como Llorente o Pascual-, y ayudados por el ingenio de Pedro de Urdemalas, que le promete un feliz desenlace gracias a las trazas que piensa llevar a cabo; dice Clemente:

Del padre el rico caudal el mío pobre desprecia por no ser al suyo igual, $\mathrm{y}$ entiendo que solo precia

6. Todo el pasaje: «Pesado contrapeso es la pobreza / para volar de amor, ¡oh Lauso!, al cielo, / aunque tengas cien alas de firmeza./ No hay amor que se abata ya al señuelo / de un ingenio sutil, de un tierno pecho, / de un raro proceder, de un casto celo./ Granjería común amor se ha hecho, / y dél hay feria franca dondequiera, / do cada cual atiende a su provecho». 
el de Llorente y Pascual, que son ricos, y es razón que se lleve el corazón tras sí de cualquier mujer, no el querer, sino el tener del oro la posesión (pp. 634-635).

Y replica Pedro:

O no tendré entendimiento, o he de trazar tus solaces.

[...]

Tú verás cómo te entrego en holganza y en sosiego el bien que interés te veda, y que al dártele preceda promesa, dádiva y ruego (p. 635).

Tras el triunfo de las estrategias de Pedro, el menos en esta comedia, el ingenio vence a todos los otros poderes:

¡Oh, cuántas cosas alcanza

la industria y sagacidad! (p. 647).

Como arma de guerra utiliza su hermosura Angélica en La casa de los celos, para apresar a los paladines, junto con el poder de la magia en la lanza encantada de Argalía (pp. 116-117, «ioh, fuerza poderosa / de la mujer que es sobre falsa, hermosa!»). Contra esa magia de la lanza actúa la también mágica protección de Malgesí y el espíritu de Merlín, que impiden que se maten entre sí los paladines, interponiendo entre ellos llamas de fuego que surgen de la tierra (p. 128), y obligándolos a retroceder con invencibles impulsos («Sube por la montaña como por fuerza de oculta virtud», «Quién mis pies ha clavado con la tierra?», «el paso sí, la voluntad no es mía», pp. 130$131,167,173)$.

No falta la versión de la magia amorosa que pretende dominar la voluntad de un sujeto para hacerle caer en los brazos del amante. El gusto cervantino, algo ingenuo, por el detallismo visual, se despliega meticulosamente en $\mathrm{El}$ trato de Argel, donde Fátima subraya en su discurso los detalles que exige el conjuro, activando así para el espectador la bizarra visualidad ${ }^{7}$ de la hechicera (pp. 855-856).

No entraré en el comentario de los poderes mágicos atribuidos a los distintos elementos que se citan, como el hipómanes o carne de la frente del potro, de famosos poderes afrodisiacos, o el muñeco de cera que representa 
a la víctima del encanto. La escena responde exactamente a las estrategias mágicas de magia amorosa, pero el demonio que acude al conjuro de Fátima -un demonio bastante racional, sicólogo y pragmático- le advierte que en un pecho cristiano las hechicerías tienen muy poca eficacia, y que es mejor confiar en la necesidad y la ocasión (p. 886).

De distinta índole son los poderes de la magia en La tragedia de Numancia (pp. 948-953), donde el mago Marquino protagoniza una larga escena necromántica, levantando un cadáver de su tumba para interrogarlo sobre el futuro de Numancia. Destaca de nuevo el detallismo en la composición visual admirable y truculenta; basta citar parcialmente las acotaciones:

Aquí sale Marquino con una ropa negra de bocací ancha, y una cabellera negra, y los pies descalzos; y en la cinta traerá, de modo que se le vean, tres redomillas llenas de agua: la una negra, la otra teñida con azafrán y la otra clara; y en la una mano, una lanza barnizada de negro, y en la otra, un libro; y viene Milvio con él, y, así como entran, se ponen a un lado Leoncio y Morandro (p. 948).

Con el agua de la redoma clara baña el hierro de la lanza, y luego hiere en la tabla; y debajo, o suéltense cohetes o hágase el rumor con el barril de piedras (p. 951).

Sale el Cuerpo amortajado, con un rostro de máscara descolorido, como de muerto, y va saliendo poco a poco, y, en saliendo, déjase caer en el teatro, sin mover pie ni mano hasta su tiempo (p. 952).

Los problemas implicados en la Numancia pertenecen ya al terreno del ejercicio del poder político, la más neta modalidad del poder que se puede contemplar y sobre la que conviene decir algunas palabras.

\section{EL PODER POLÍTICO}

Si la forma más nítida del poder es la política (con algunos otros espacios de dominio del actante "poderoso" sobre los súbditos o subordinados $)^{8}$ nada de extraño será hallar casos de gobernantes con rostros diversos. Ya me he referido al examen de cuatro figuras de rey que hace Canavaggio, en el que distingue el papel secundario de Hassán Pachá, «rey de Argel» en El trato de Argel, que es un modelo negativo de ejercicio tiránico del poder («Hassan apparaît donc comme le type même du potentat qui s'abandone à ses passions au lieu de se laisser guider par la raison» $)^{9}$ frente a la evocación de Felipe II, restaurador de la religión verdadera (p. 856). Cierto cambio -que no veo tan claro como lo ve Canavaggio - en la actitud de Hassán, que acaba mostrando admiración por los españoles, lo interpreta el estudioso como inexperiencia

8. Como en el ámbito doméstico la presión de los actantes paternos sobre las hijas.

9. Véase El trato de Argel (pp. 909-911) para algunos ejemplos de la violencia tiránica de este rey. 
de «un dramaturge débutant», que en el mismo personaje reúne tanto la figura del tirano violento como del rey justiciero. Sería, a mi juicio, discutible la vertiente de rey justiciero en Hassán, y más evidente en el Gran Turco de $L a$ gran sultana, aunque en este caso la actitud del rey se debe al influjo del amor por una cristiana, como ya he comentado más arriba. Lo más llamativo en este sentido es la puesta en escena de los rituales del poder (pp. 374-375):

Parece el Gran Turco detrás de unas cortinas de tafetán verde; salen cuatro bajaes ancianos; siéntanse sobre alfombras y almohadas; entra el embajador de Persia, y al entrar le echan encima una ropa de brocado; llévanle dos turcos de brazo, habiéndole mirado primero si trae armas encubiertas; llévanle a asentar en una almohada de terciopelo; descúbrese la cortina; parece el Gran Turco. (Mientras esto se hace pueden sonar chirimías) (pp. 402-403).

Muy poca importancia tiene el rey en Los baños de Argel, y más interesante es el de Pedro de Urdemalas, que Canavaggio caracteriza como una autoridad farsesca en una atmósfera de fantasía. En esta comedia «le personnage du roi nous apparaît sous un jour insolite qui lui assure une incontestable originalité», «cette pièce nous offre, dans une atmosphère de pure fantaisie, le nec plus ultra de la réélaboration cervantine de la figure du roi. Il n'y a plus, cette fois, de référent historique auquel renvoie le personnage». En efecto, se trata de un rey que se prenda de una gitana y se dispone a gozar de ella entregado a su deseo como un tirano de tono menor:

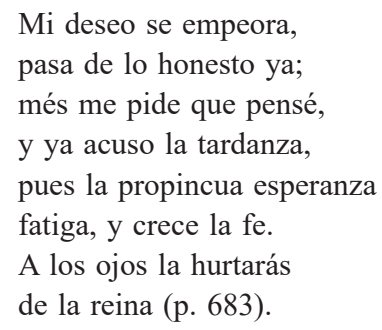

La reina por su parte, llevada de los celos, ordena detener a las gitanas (p. 690). Ambos monarcas, como subraya Pedro, se dejan llevar de sus pasiones y actúan movidos de la ira:

... que las iras de los reyes

pasan términos y leyes,

como es su fuerza suprema (p. 692).

Se descubre que la hermosa Belica es en realidad sobrina de la reina, y mientras esta aminora sus celos con poca justificación («que entre mis celos y vos / se ha puesto el ser mi sobrina», dice al rey, p. 717), el rey no ceja en sus intenciones: 
Rey Gitana, me tuvo muerto; dama, a matarme se adiestra.

El parentesco no afloja mi deseo; antes, por él con ahínco más cruel toda el alma se congoja (p. 714).

Silerio No te aflijas, que no es tanto el parentesco que impida hallar a tu mal salida.

Rey Sí, mas moriré entretanto (p. 718).

El espectador quedará sin saber el desenlace de estas pretensiones del rey porque la obra termina con el anuncio de otra comedia que va a representar la compañía de Pedro, interrumpiéndose la acción principal, aunque la actitud soberbia de Belilla la coloca en la vía de corrupción del rey. Que haya una «descarnada mirada» final sobre la realeza ${ }^{10}$ puede aceptarse, sin darle excesiva trascendencia política a estas figuras un tanto caricaturescas que se mueven en un mundo folklórico y de imaginación.

Plenamente paródica es la visión del poder y la autoridad que se desprende de La elección de los alcaldes de Daganzo, como corresponde al género del entremés. Todas las habilidades de estos pretendientes al gobierno municipal son grotescas (Berrocal es gran mojón y catavinos; Jarrete un águila en tirar con arco de bodoques; Pedro de la Rana se sabe todas las coplas del perro de Alba y Humillos «un zapato remienda como un sastre», pp. 754-755). En el examen de los candidatos asoman temas como el soborno (pp. 756-757), la ignorancia y el temor a la Inquisición (p. 757), los méritos ridículos alegados... ${ }^{11}$ Rana, sin embargo, cuando manifiesta sus condiciones declara un arte de gobierno perfectamente válido, más allá de su ocasional expresión rústica:

\section{Como Rana,}

habré de cantar mal; pero, con todo, diré mi condición, y no mi ingenio. Yo, señores, si acaso fuese alcalde, mi vara no sería tan delgada como las que se usan de ordinario: de una encina o de un roble la haría, y gruesa de dos dedos, temeroso que no me la encorvase el dulce peso de un bolsón de ducados, ni otras dádivas, o ruegos, o promesas, o favores, que pesan como plomo, y no se sienten hasta que os han brumado las costillas

10. Sosa (2006: p. 906). Es más que dudosa la identificación que hace algún estudioso de los reyes y Silerio con Felipe III, Margarita de Austria y el Duque de Lerma; véase Sosa (2006: p. 905).

11. Para las dimensiones críticas de esta política municipal, véanse González Maestro (2005) y Martínez Bennecker (2012). 
del cuerpo y alma; y, junto con aquesto, sería bien criado y comedido, parte severo y nada riguroso; nunca deshonraría al miserable que ante mí le trujesen sus delitos; que suele lastimar una palabra de un juez arrojado, de afrentosa, mucho más que lastima su sentencia, aunque en ella se intime cruel castigo. No es bien que el poder quite la crianza, ni que la sumisión de un delincuente haga al juez soberbio y arrogante (pp. 759-760).

En el extremo opuesto del terreno cómico se coloca la tragedia de Numan$\mathrm{cia}^{12}$, que explora nuevas dimensiones del poder y de la autoridad. Una de las vertientes se establece entre Cipión y el ejército romano: la primera tarea de general es imponer su autoridad y regenerar las corruptas tropas que cercan a Numancia. Desde este punto de vista Cipión se configura como un general sumamente eficaz, con perfecto conocimiento de las estrategias del mando (cfr. pp. 929-930).

Un segundo aspecto del poder es el que enfrenta a Roma con Numancia, y que involucra el tema central de la libertad y la resistencia frente a la opresión. La rebeldía de Numancia se presenta como respuesta contra el yugo de cónsules tiranos (p. 927), y aunque Cipión es consciente de la degradación anterior de los soldados y autoridades de Roma, se niega a firmar la paz con quienes se han opuesto al poder imperial con tan notable éxito (p. 928).

Frente a la postura de Cipión -indispensable desde el punto de vista dramático para conducir la tragedia, cuya acción, por otra parte viene definida por la leyenda y la historia- se alza la vocación de libertad de los numantinos:

¡Oh, muros deste ciudad!, si podéis hablar, decid y mil veces repetid: ¡Numantinos, libertad! (p. 961).

Numancia se configura en parte como símbolo de España («quedará sujeta España / al senado romano, solamente / con vencer la soberbia de esta gente», p. 930), sometida siempre a naciones extranjeras -como se queja la misma figura alegórica de España-, a causa de sus discordias internas:

... con sus discordias convidaron

los bárbaros de pechos codiciosos

12. No entro en la abundante bibliografía y comentarios sobre el tema de la libertad, etc. que se han dedicado a esta pieza, ni tampoco en las diversas interpretaciones de Roma y Numancia como por ejemplo, la que identifica a los numantinos con los moriscos de las Alpujarras (poco aceptable a mi juicio), etc. Véase Cortadella (2005) y Bauer Funke (2011). 
a venir a entregarse en mis riquezas, usando en mí en el ellos mil cruezas. Numancia es la que agora sola ha sido quien la luciente espada sacó fuera, y a costa de su sangre ha mantenido la amada libertad suya y primera (p. 931).

La esperanza de que estas divisiones interiores cesen se expresa en forma profética en la intervención del Duero (pp. 933-936), que augura sobre las cenizas de Numancia el renacer de España y la grandeza en el futuro reinado de Felipe II, cuya figura mitificada reaparece con parecidos perfiles, mucho más amplios, que en El trato de Argel:

... un rey será de cuyo intento sano grandes cosas me muestra el pensamiento; será llamado, siendo suyo el mundo, el segundo Felipe sin segundo.

Debajo de este imperio tan dichoso, serán a una corona reducidos, por bien universal y a tu reposo, tus reinos, hasta entonces divididos. El jirón lusitano, tan famoso, que un tiempo se cortó de los vestidos de la ilustre Castilla, ha de asirse de nuevo, y a su antiguo ser venirse. ¡Qué envidia, qué temor, España amada, te tendrán mil naciones extranjeras, en quien tú reñirás tu aguda espada y tenderás triunfando tus banderas! Sírvate esto de alivio en la pesada ocasión por quien lloras tan de veras, pues no puede faltar lo que ordenado ya tiene de Numancia el duro hado (pp. 935-936).

\section{EL PODER DE DIOS}

En el variado territorio del teatro cervantino todavía hay un espacio de poder que se eleva sobre todos los demás: es el poder de Dios y de su misericordia en la comedia El rufián dichoso. Y también el poder del arrepentimiento, el llanto y la oración. La estructura que veía Casalduero en la comedia («La primera jornada es la del pecado, la segunda la del arrepentimiento, la tercera la del perdón, santidad y milagros» $)^{13}$ ha sido corregida razonablemente por Villanueva, quien apunta:

13. Casalduero (1966: 109), cit. por Villanueva (2001). Véase Delgado (2005), que hace una buena aproximación y discute interpretaciones desviadas aunque considera que el protagonista sufre una conversión radical, que es menos radical de lo que parece, según acabo de apuntar. 
En realidad, de acuerdo con la letra y el espíritu de la comedia, lo atribuido por Casalduero a la primera y segunda jornadas (la primera, el pecado; la segunda, el arrepentimiento) se reduce a la primera; [...] Valoración teológica aparte, el arrepentimiento-decisión de cambiar de vida sucede en el acto inicial $[\ldots]$.

En nuestra lectura particular de El rufián dichoso, nos enfrentamos a algo más que a una comedia hagiográfica. Cervantes dio un paso más para adentrarse en los vericuetos de la teología. Ciertamente la comedia incluye dos conversiones; pero difiere por completo el punto de partida de ambas: Cristóbal de Lugo pasará a ser Cristóbal de la Cruz desde un planteamiento de fe nunca perdido (su vida de valentón y ligero de lengua tiene, en la otra parte del fiel de la balanza, el rezo del rosario, la limosna al ciego exigiéndole oraciones por las ánimas del purgatorio, la ayuda al marido expuesto al adulterio, el rechazo de la lujuria en el caso de la prostituta Antonia). Por el contrario, el personaje de Ana Treviño aparece como hundido en la incredulidad-ateísmo [...] y la desesperación, convencida como está la pecadora de la imposibilidad de lograr el perdón divino a causa de la multitud y gravedad de sus pecados (Villanueva 2001: pp. 452453).

En efecto, Cristóbal guarda siempre - como los pecadores devotos de Berceo- un resto de fe y de caridad que anuncian su conversión definitiva. Mantiene siempre, por ejemplo, la devoción del rosario ${ }^{14}$ y el rosario será su coraza final en la batalla contra los demonios. Baste citar la escena de la apoteosis del santo:

Traen al santo tendido en una tabla, con muchos rosarios sobre el cuerpo; tréenle en hombros sus frailes y el virrey; suena lejos música de flautas o chirimías; cesando la música, dice a voces dentro Lucifer; o, si quisieren, salgan los demonios al teatro.

Lucifer Aun no puedo llegar siquiera al cuerpo, para vengar en él lo que en el alma no pude: tales armas le defienden.

Saquiel No hay arnés que se iguale al del rosario.

Lucifer Vamos, que en solo verle me confundo (p. 370).

Pero no es en Cristóbal donde se centra la exaltación del poder de la misericordia divina, sino sobre todo en la desesperada doña Ana, que disputa con un clérigo sobre la capacidad de Dios para manejar la culpa del pecador:

\author{
Doña Ana No me canse ni se canse \\ en persuadirme otra cosa, \\ que no soy tan amorosa \\ que con lágrimas me amanse.
}

14. Siendo valentón, lleva a las espaldas el broquel y la daga, pero el rosario en la mano (p. 311), y en el rosario confía siempre («aunque peco de ordinario, / pienso, y ello será ansí /dar buena cuenta de mí / por las de aqueste rosario», p. 313). 


$\begin{array}{ll} & \text { ¡No hay misericordia alguna } \\ \text { que me valga en suelo o cielo! } \\ \text { Clérigo } \quad \text { Toda la verdad del cielo } \\ \text { a tu mentira repugna. } \\ \text { En Dios no hay menoridad } \\ \text { de poder... (p. } 344) .\end{array}$

Y un poco más adelante:

La mayor ofensa haces

a Dios que puedes hacer, que, en no esperar y temer, parece que le deshaces, pues vas contra el atributo que él tiene de omnipotente... (p. 345).

Pero con la omnipotencia divina puede colaborar el hombre con instrumentos que soliciten el perdón, el arrepentimiento, la conversión. En El rufián dichoso aparecen privilegiados el citado rosario (el poder de la oración), el llanto, y la caridad con la que Cristóbal ejerce de figura cristológica, asumiendo - como hizo Cristo para todo el género humano- los pecados de doña Ana ${ }^{15}$.

\section{FINAL}

Múltiples son, en suma, las caras del poder en el teatro cervantino, y numerosas las instancias de dominio que trasminan las relaciones de los personajes, ya sea en sus dimensiones particulares o sociales. Los poderes del amor, de la magia, del interés, el poder paterno y el político, y hasta la omnipotencia de Dios se revelan en las piezas de Cervantes, en caras variadas que adquieren no menos variadas expresiones según los géneros dramáticos implicados. Aunque los problemas y las facetas del poder y la autoridad no se coloquen siempre en un primer plano, siempre están de un modo u otro activos en las preocupaciones cervantinas, porque en relación -a menudo conflictiva- con el poder se halla el que quizá sea el mayor de los temas que caracterizan la cosmovisión creadora de Cervantes: el gran tema de la libertad, la cara inversa -casi siempre- del poder.

\section{FUENTES}

Alciato, Andrea (2003). Los emblemas de Alciato traducidos en rimas españolas [por Bernardino Daza Pinciano], Rafael Zafra (ed.). Palma de Mallorca: Olañeta. 


\section{BIBLIOGRAFÍA CITADA}

Arellano, Ignacio (1995). «Valores visuales de la palabra en el espacio escénico del Siglo de Oro», Revista Canadiense de Estudios Hispánicos. 19 (3), pp. 411-443.

Arellano, Ignacio (1997). «Motivos emblemáticos en el teatro de Cervantes», Boletín de la Real Academia Española. 77, pp. 417-443.

Arellano, Ignacio (2005). «Escenario y puesta en escena del teatro cervantino», Boletín de la Real Academia Española. 85, pp. 29-52.

Arellano, Ignacio (2011). Los rostros del poder en el Siglo de Oro. Ingenio y espectáculo. Sevilla: Renacimiento.

Arellano, Ignacio; Feros, Antonio y Usunáriz, Jesús María (ed.) (2012). Del poder y sus críticos en el mundo ibérico del Siglo de Oro. Madrid/Frankfurt am Main: Iberoamericana/Vervuert.

Arellano, Ignacio; Strosetzki, Cristoph y Williamson, Edwin (ed.) (2009). Autoridad y poder en el Siglo de Oro. Madrid/Frankfurt am Main: Iberoamericana/Vervuert.

Baraibar, Álvaro e Insúa, Mariela (ed.) (2012). El universo simbólico del poder en el Siglo de Oro. Nueva York/Pamplona: Instituto de Estudios Auriseculares (IDEA)/Servicio de Publicaciones de la Universidad de Navarra.

Bauer Funke, Cerstin (2011). «El cerco de Numancia de Cervantes: Un discurso heterodoxo en la España imperial», en Carmen Rivero Iglesias (ed.), Ortodoxia y heterodoxia en Cervantes. Alcalá de Henares: Centro de Estudios Cervantinos, pp. 33-42.

Canavaggio, Jean (2017). "Autorité et Pouvoir dans le théâtre de Cervantès», Bulletin hispanique. 119 (1), pp. 79-88, doi: https://doi.org/10.4000/bulletinhispanique.4768.

Casalduero, Joaquín (1966). Sentido y forma del teatro de Cervantes: Madrid: Gredos.

Cervantes, Miguel de (1987). Teatro completo, Florencio Sevilla Arroyo y Antonio Rey Hazas (ed.). Barcelona: Planeta.

Cortadella, Jordi (2005). «La Numancia de Cervantes: paradojas de la heroica resistencia ante Roma en la España imperial», en Actas del XI Coloquio internacional de la Asociación de Cervantistas. Seoul: Universidad Hankuk de Estudios Extranjeros, pp. 557570.

Delgado, Manuel (2005). «Itinerario moral de Cristóbal de Lugo», en Kurt Reichenberger y Darío Fernández-Morera (coord.), Cervantes y su mundo, vol. 3. Kassel: Reichenberger, pp. 103-122.

Garau, Jaime (2010). «De la predicación en tres comedias de Cervantes. El trato de Argel, Los baños de Argel y El rufián dichoso», Anales Cervantinos. 42, pp. 177-191.

González Maestro, Jesús (2005). «Cervantes y el entremés, poética de una comicidad crítica», en XII Coloquio Internacional de la Asociación de Cervantistas. Argamasilla de Alba: Universidad de Castilla-La Mancha, pp. 525-536.

Henkel, Arthur y Schöne, Albrecht (1967). Emblemata. Weimar: Metzler.

Insúa, Mariela y Schmelzer, Felix K. E. (ed.) (2013). Teatro y poder en el Siglo de Oro. Pamplona: Servicio de Publicaciones de la Universidad de Navarra, 2013.

Lourenço, Antonio Apolinário y Usunáriz, Jesús María (ed.) (2012). Poderes y autoridades en el Siglo de Oro: realidad y representación. Pamplona: EUNSA.

Martínez Bennecker, Juan B. (2012). «Comicidad crítica en La elección de los alcaldes de Daganzo», Lemir. 16, pp. 271-282.

Pinillos, María Carmen (1997). «Emblemas en el Quijote. El episodio de las bodas de Camacho», Criticón. 71, pp. 93-104.

Sosa, Marcela (2006). «Estrategias metateatrales en Pedro de Urdemalas y su relación con la poética del Quijote», en Alicia Parodi, Julia D’Onofrio y Juan Diego Vila (coord.), El Quijote en Buenos Aires: lecturas cervantinas en el cuarto centenario. Buenos 
Aires: Universidad de Buenos Aires, Instituto de Filología y Literaturas Hispánicas Dr. Amado Alonso, pp. 901-908.

Villanueva, Juan Manuel (2001). «El Rufián Dichoso ¿es una típica comedia de santos?», en Cervantes en Italia. Actas del X Coloquio Internacional de la Asociación de Cervantistas. Academia de España, Roma, 27-29 septiembre 2001. Palma de Mallorca, pp. 449-457.

Williamson, Edwin y Usunáriz, Jesús María (ed.) (2013). La autoridad politica y el poder de las letras en el Siglo de Oro. Madrid/Frankfurt am Main: Iberoamericana/Vervuert.

Recibido: 29 de junio de 2016

Aceptado: 3 de julio de 2017 